\title{
Educational Modules of Skeletal Muscle Anatomy and Function with Models and Active Data Gathering Related to Muscular Dystrophy
}

\author{
Robin L. Cooper ${ }^{1,4}$, Rebecca M. Krall ${ }^{2,}$ Michael P. Schultz ${ }^{1,3}$, Ann S. O’Neil ${ }^{1}$, \\ Esther E. Dupont-Versteegden ${ }^{4,5}$
}

${ }^{1} 675$ Rose St, Department of Biology, University of Kentucky, Lexington KY 40506-0225 USA

${ }^{2} 105$ Taylor Education Bldg, 597 S. Upper St, Department of STEM Education, University of Kentucky, Lexington KY 40406-0001 USA

${ }^{3} 800$ Rose St MN 150, College of Medicine, University of Kentucky, Lexington KY 40536-0200 USA

${ }^{4}$ Charles T. Wethington Jr. Building, 900 South Limestone, University of Kentucky, Lexington KY 40536-0200 USA

${ }^{5}$ Center for Muscle Biology, 900 South Limestone, University of Kentucky, Lexington KY40536-0200 USA (RLCOOP1@uky.edu; rebecca.krall@uky.edu; mschultz@pennstatehealth.psu.edu; asc1029@gmail.com; esther.dupont@uky.edu)

\begin{abstract}
An emphasis in education is the application of integrated STEM knowledge to explore potential transdisciplinary solutions to real-world problems. The goal of this problem-based module is to develop the learner's STEM content knowledge they apply in explaining a human health issue - muscular dystrophy. The module opens with a classmate that has recently been diagnosed with muscular dystrophy and is seeking help from peers to learn about this disease. Concepts addressed include skeletal muscle anatomy and physiology, and the cellular physiology of the muscle cell; which are applied in formulating explanations describing muscle cell function in healthy individuals and those with a disease. Students conduct literature research and investigate muscle cell function to learn the anatomy and physiology of healthy and diseased muscle tissue. Subsequent engineering design activities challenge teams to build 2-D and 3-D models used in explaining muscular dystrophy to their friend. Team presentations incorporate the testing and feedback needed to modify models to provide the best tools for explaining the disease.
\end{abstract}

Keywords: Skeletal, anatomy, physiology, models

Link to Original Poster File: https://doi.org/10.37590/able.v41.poster64

\section{Introduction}

Skeletal muscle comprises about $33 \%$ to $50 \%$ of one's body weight and is the largest internal organ. It allows us to move our body parts and respond to various types of stimuli for survival. Skeletal muscle grows and shrinks based on use and it has an amazing ability to repair itself. Understanding how skeletal muscle functions from a cellular level to the macroscopic level of the whole muscle tissue is important in understanding how it functions under normal conditions as well as in diseased states. Various pathological conditions have an impact on skeletal muscle such as obesity, depression and other neural disorders.

Learning is context dependent. That is, what students learn is closely linked to the situation in which the learning occurs, individuals with whom they collaborate in their learning, and the context in which content is presented (Goel et al. 2010). Socioeconomical changes such as in interest, values, and identity are closely linked with students' motivation to learn and contribute to what they learn (Lemke, 2001; Shweder et al. 1998). Having interest and curiosity about content taught inspires motivation to learn and understand (Marx et al. 1997; National Research Council. 2005). 
Incorporating a real world issue relating to muscle function can further build interest and purpose for study (Marx et al., 1997; Krajcik \& Czerniak, 2014). Therefore, engaging students in the study of skeletal muscle from their own bodies can provide context, create interest, affect identity, and has the potential to pique curiosity. Such experiences also can motivate students to learn concepts and principles used to explain their own observations and describe how the disease state of muscular dystrophy affects muscle physiology.

The exercises presented here place students in the role of a class tasked with learning about muscular dystrophy to help a classmate that has recently been diagnosed with muscular dystrophy to better understand the disease. The sequence of activities follows an experimental design model where students test hypotheses to identify a relationship of muscle size to rate of fatigue as they explore force generated in the biceps. They combine their findings with research they conduct on muscular dystrophy to create models and find explanations to share with their classmate and his family. Extensions of the provided protocol can easily be adapted for student-driven inquiry or problem-based learning.

Simple inexpensive data collection software is currently available for use on smart phones, iPads, or tablets. These apps collect data to measure the force and contraction of skeletal muscles. Other inexpensive devices, such as the EMG Spiker Box (https://backyardbrains.com/), plug into smart technology providing alternative software for collecting data. Smart phone and notebook technology also offer the flexibility to perform data collection anywhere. The Backyard Brains device requires some simple soldering for students to make their own recording devices

Assembling the device is not difficult and offers students in middle school through college opportunities to build these recording units. Engineering design (Next Generation Science Standards, NGSS Lead States, 2013) activities also could be created to explore different materials used to create the recording devices. Data collected through smart technology can be easily transferred to other devices for analysis. Recorded files saved to smart phones or iPads can be downloaded and saved to a computer or emailed to be graphed in Excel or another spreadsheet program. The graphical representations can be compared across different times in the experiment, such as at the initial stage and fatigued stage, or the amount of activity related to the weight being lifted. In addition, the files can be played back on a smart phone or other technology as audio files. The detailed procedures from the Backyard Brains web site details how to set up and use the equipment.

A video showing the exercises described herein is provided (see youtube website):

https://www.youtube.com/watch?v=e8BrVmYywZw\&fea ture=youtube

along with sample pre- and post- test questions for middle and secondary level students. 


\section{Student Outline}

\section{Objectives}

Students will learn:

- the anatomy of the contractile units of skeletal muscle

- $\quad$ how to model the contractile units of skeletal muscle

- the physiology of muscle contraction

- how the disease of muscular dystrophy relates to the structure and function of skeletal muscles

- the nature of the disease of muscular dystrophy and its ramifications

- how to distill and use literary recourses related to muscular dystrophy for

- how to compile and present the information they have learned to others

\section{Introduction}

You and your classmates have just learned that a peer in your class has recently been diagnosed with muscular dystrophy. The student and his family are trying to better understand the disease. Your teacher thinks this is a great idea for your class to research as long as the student and his parents are willing to accept help from the class.

To be able to manage this adventure, the teacher will divide the class into groups of four or five students. Each group will complete the first activity in the module. Thereafter, each group will be subdivided into two groups to complete one of the following activities

(1) Create a physical model of a sarcomere (muscle contractile unit) with accompanying written explanations to describe the cellular anatomy and to illustrate differences between healthy and diseased states.

(2) Conduct a literature search on the disease process of muscular dystrophy and its treatments. Construct a written summary with drawn diagrams or 3-D models to illustrate differences in the disease state of sarcomeres in persons with muscular dystrophy.

Once the information is collected, the groups will discuss possible ways to effectively present the information learned through the research to other classmates and to the public as a public awareness poster or display. Then each group of four or five will develop a presentation project to be shared with an audience or presented at a local public event. Instructions for each of the four components of the module follow.

\section{Task 1: Measuring Electromyogram (EMG) in Your Muscles}

To be completed by each group of four or five students.

When contraction of a skeletal muscle is initiated, the electrical activity generated from the movement of ions produces electrical potentials that can be picked up with surface electrodes on the skin. The electrical activity monitored from muscle is referred to as the electromyogram (EMG) in Figure 1. The frequency, amplitude and profile of the signals can be related to muscle function (Bergquist \& Hammert, 2013; Ghaoui et al. 2013).

Purpose: In this activity, you will collect electrical activity data from your muscles to compare differences in muscle activity when at rest, during contraction with varying weights, and once the muscle is fatigued.

\section{Making a Hypothesis}

Your muscles generate electrical activity from the movement of ions. Make hypotheses to answer each of the following questions.

1. How much electrical activity would you expect to measure when your muscles are at rest?

2. How will the electrical activity of muscles change when you move from a resting state to contracting as you lift a weight? 
3. What would you expect to see in the electrical activity output when a muscle is fatigued?

4. Will electrical activity in similar states vary across students? What do you expect to observe?

\section{Conducting the Activity}

The EMG probes used in this module (Backyard Brains https://backyardbrains.com/experiments/musclespikerbox) will pick up electrical activity produced from muscles. Procedures that follow guide the collection of electrical activity data produced from the muscles to test the hypotheses given above.

Alternatively, create procedures using your own steps to test whether the above hypotheses are supported. The EMG probes used in this activity will pick up electrical activity in your muscles whether in a relaxed state, a contracted state, or when fatigued. Possible plans might include collecting electrical activity data from a specific location of the bicep of a dominant arm and then a non-dominant arm. Holding a weight compared to hanging the arm along the body in a relaxed state also can show changes in electrical activity. Also, observe what happens over the duration of muscle contraction. Notice any changes in the electrical activity after a long period of contraction. An example of this activity is shown on a YouTube link (https://www.youtube.com/watch?v=e8BrVmYywZw\&feature=youtube).

EMG probe data recorded on the iPad or iPhone will look similar to the data shown in Figure 1.
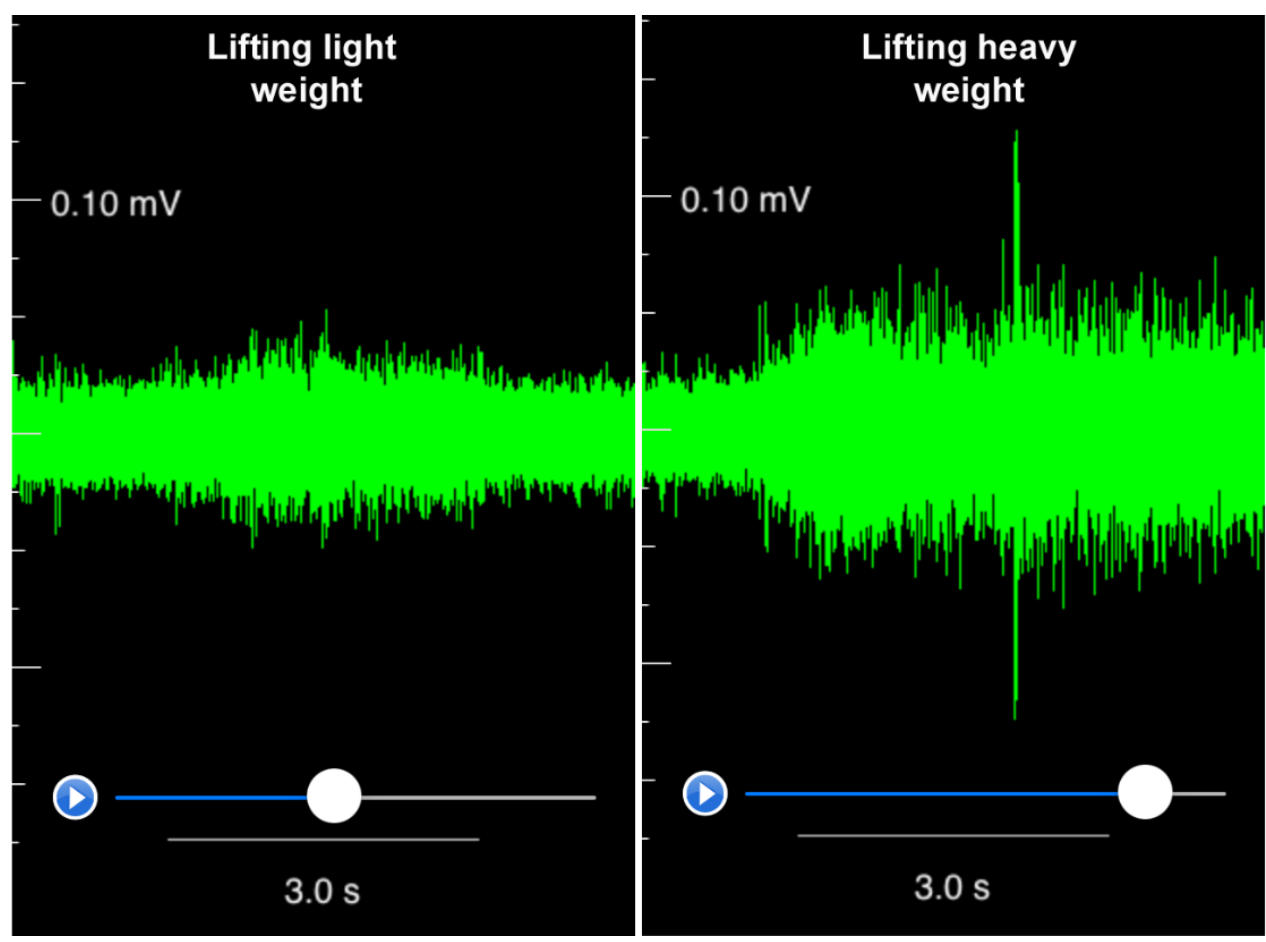

Figure 1. EMG recordings obtained with an iPad while using the Backyard Brains EMG unit. The recording on the left is while lifting a light weight and the recording on the right is while holding a heavier weight. These recordings were made of the biceps muscle.

\section{Procedures for EMG Measures}

1. Download free Backyard Brain app to iPhone or iPad.

2. Set up Backyard Brain EMG recording

3. Measure biceps EMG in dominant arm: Before lifting weight, light weight to elbow flexion of 90 degrees 
4. Measure how long until fatigue occurs with a light weight. (Record time to fatigue in Table 1)

5. Repeat above but with more weight (Measure biceps EMG before lifting weight, during lifting of heavy weight to 90 degrees).

6. Measure how long until fatigue occurs with a heavy weight (record time to fatigue in Table 1)

7. Increase mental focus to override the fatigue

8. Repeat the experiments with measuring the EMG activity with greater than 90 degrees at the elbow with heavy weight.

9. If time permits repeat the fatigue experiment with non-dominant arm with heavy weight.

10. Weigh on a scale the light weight and heavy weights used in the experiments.

11. Collect variables on the experimenter: upper arm circumference, gender, what type of exercises they may perform with their upper arms, how the person feels on the day of experiment, information on use of their upper arms within the last 24 hours.

Table1. Measure of time to fatigue.

\begin{tabular}{|l|l|l|l|}
\hline & Time to Fatigue & Weight of objects (grams) & $\begin{array}{l}\text { Experimenter } \\
\text { Information }\end{array}$ \\
\hline Light Weight & & & \\
\hline Heavy Weight & & & \\
\hline
\end{tabular}

\section{Questions to Answer after Data is Collected}

1. Looking over the data and thinking about what you have learned about muscles, how can you explain the results for lifting weights of different amounts?

2. What causes fatigue and how does lifting weight relate to fatigue?

3. Looking at the data in Table 1, what is the relationship between the time to fatigue and the amount of weight?

4. What suggestions would you make to help recover from fatigued skeletal muscles?

5. What might you suggest if a heavy object needed to be carried by hand, such as the books on a rope in these experiments?

6. If an experiment was conducted with the dominant and non-dominant arms, were there differences in the time to fatigue for the same amount of weight lifted? Explain the results.

\section{Additional Investigations to Explore:}

If this activity is done in a classroom with many people, measure upper arm circumference and describe the relationship between time of fatigue and the mass held. (When measuring circumference, place the forearm on a tabletop with the elbow bent at 90 degrees so the biceps is at a resting state and not contracted.) Combine the class data. What kind of relationship is there between the biceps circumference and the time to fatigue? 


\section{Tasks 2: Anatomy of the Sarcomere}

To be completed collaboratively by two or three students from each group.

Conduct a literature search to learn how the smallest contractile unit from skeletal muscle, called a sarcomere, works in a healthy state. Look for the basic anatomy of skeletal muscle cells and learn how muscle contraction occurs. Reading a section in an introductory biology or physiology textbook should suffice, but the library might have other books that will be helpful, too. After learning about the anatomy of the sarcomere, draw a diagram of three sarcomere units for two different states of skeletal muscle. One state is a relaxed state with the sarcomere stretched out, and the second drawing of the muscle is in a contracted state with shortened sarcomeres. In both drawings, label the following information:

Actin, myosin, thin filament, thick filament, Z-disk, and where the myosin heads are located.

Then carefully list the bands A, H, I, M-line. Note which bands change in dimension and which ones do not with muscle contraction and relaxation.

In a third drawing, show an enlarged view of the thin filament with the two actin strands twisted along with the troponins (troponin C, troponin I, and troponin T) and the protein tropomyosin. Then label where an active site might be located for a myosin head to bind. Label the locations of the troponins around an active binding site and illustrate interaction with tropomyosin structure.

The drawings you created show the contractile proteins for skeletal muscle contraction. But there are many more proteins needed for the skeletal muscle to function correctly. More recent research has identified structural proteins, such as titin and those that hold the contractile machinery to the plasma membrane (muscle cell membrane), but not all of the textbooks have been updated to include these important molecules.

Introductory biology or physiology books probably will not include titin in the skeletal muscle description. Conduct a search online for information. Searching the internet for "titin" will give a lot of odd hits not related to muscle. Using key words such as "muscle titin sarcomere" will provide better success in finding images to learn how titin connects to the contractile elements, and where dystrophin is located. You might find other proteins in figures or in the literature when conducting searches on this topic, but titin and dystrophin are the essentials for this exercise.

Return to your drawings of the sarcomeres. In each diagram, draw the plasma membrane, titin and dystrophin around the figure of the three sarcomeres. Show how the protein dystrophin fits into the anatomical scheme of the muscle and the extracellular matrix on the outside of the muscle.

Now knowing where dystrophin is located in relation to the contractile units, address what would happen if dystrophin was removed from the cell. What would happen if there was a mutation in the protein sequence? Explain what would happen if there was not any dystrophin, or if a mutated form of dystrophin affects the forces from the contractile elements to the plasma membrane.

\section{Physiology}

Go through a stepwise process to explain how skeletal muscle contracts as the muscle membrane (sarcolemma) is depolarized due to acetylcholine release from the motor nerve terminal.

In your response, identify the following sequences in the correct order beginning with muscle depolarization at the junction of the motor nerve to the muscle fiber (order should be mixed when this list is provided to students):

- Acetylcholine (ACh) causes depolarization of the plasma membrane of the muscle

- An action potential travels along the plasma membrane and down T- tubules.

- The sarcoplasmic reticulum (SR) inside the muscle cell releases $\mathrm{Ca}^{2+}$ to then raise $\mathrm{Ca}^{2+}$ within the cytoplasm inside the muscle.

- $\mathrm{Ca}^{2+}$ ions bind with troponin causes tropomyosin to move and an active site is exposed on actin for the myosin head

- $\quad$ Myosin binds to actin

- Contraction starts and the sarcomeres shorten 
- The myosin heads release the ADP, and Pi and comes of the active site while the head rotates back and return to be ready to bind to an active site again

- $\mathrm{Ca}^{2+}$ levels return to a lower level in the cytoplasm

Tasks 3: Making Sense of Muscular Dystrophy

To be completed collaboratively by two or three members from each group.

Your group is tasked with learning about the disease process of muscular dystrophy and treatments. Conducting a literature search using an online search engine such as Google Scholar will provide quick access to information. What follows are some key words to get you started.

$$
\begin{aligned}
& \text { muscular dystrophy define } \\
& \text { types of muscular dystrophy } \\
& \text { what is muscular dystrophy }
\end{aligned}
$$

After some investigation, clarify the various forms of muscular dystrophy. You might find that creating a table will help organize your research.

Next, search the internet to find out how muscular dystrophy develops. Some key words to use are:

causes of muscular dystrophy

genetics muscular dystrophy

Now list the various causes known for developing the various types of muscular dystrophy.

Next search on internet on treatments and therapy for muscular dystrophy. Some key words to use are:

$$
\begin{aligned}
& \text { therapy for muscular dystrophy } \\
& \text { treatment of muscular dystrophy }
\end{aligned}
$$

\section{Task 4: Public Awareness Information Display or Poster}

To be completed collaboratively by two or three members from each group.

The task for this group is to develop an effective way for presenting to classmates and in a public awareness poster, Piktochart (https://piktochart.com/) or display the information learned through the research on muscle cells and muscular dystrophy. Obtain the information from meeting with students from Groups 1 and 2 separately to discuss what they have learned about (1) how the muscle works and (2) the disease process of muscular dystrophy and treatment. Then discuss creative informative ways to share the information to another class or at a school or public event.

Here are some ideas:

- One approach could be to create a poster or a Piktochart to illustrate sarcomeres and how they work, and what happens in the disease state of muscular dystrophy and possible treatments.

- $\quad$ Another approach might be to plan a 3-D display to illustrate the information. Some display items could include 3-D models constructed to show healthy working muscle cells in comparison to muscle cells in disease state of muscular dystrophy. Other hands-on activities could be planned around a tabling event, such as EMG activities models, and other pamphlets distributed to the public.

The following points should be included in the presentation or display:

1. The anatomy of skeletal muscle and how muscle contraction occurs 
2. Define muscular dystrophy and how the disease occurs

3. The types of muscular dystrophy and differences in the forms.

4. Show where the dystrophin complex is located and how this can affect muscle strength and weakness

5. The current treatments and therapy for muscular dystrophy.

\section{Cited References}

Backyard Brains 2017. Muscle spiker box. Available from https://backyardbrains.com/

Bergquist ER, Hammert WC. 2013. Timing and appropriate use of electrodiagnostic studies. Hand Clinics 29(3):363-370. doi: 10.1016/j.hcl.2013.04.005

Ghaoui R, Clarke N, Hollingworth P, Needham M. 2013. Muscle disorders: the latest investigations. Internal Medicine Journal 43(9):970-978. doi: 10.1111/imj.12234.

Goel L, Johnson N, Junglas I, Ives B. 2010. Situated learning: Conceptualization and measurement. Decision Sciences Journal of Innovative Education 8(1):215-240.

Krajcik JS \& Czerniak CM, 2014. Teaching Science in Elementary and Middle School: A Project-Based Approach. London: Routledge.

Marx RW, Blumenfeld PC, Krajcik JS, Blunk M, Crawford B, Kelly B, Meyer KM. 1994. Enacting project-based science: Experiences of four middle grade teachers. The Elementary School Journal 94(5):517-538.

National Research Council. 2005. How Students Learn: History, Mathematics, and Science in the Classroom. Washington, DC: The National Academies Press. https://doi.org/10.17226/10126.

NGSS Lead States. 2013. Next Generation Science Standards: For States, By States. Washington, DC: The National Academies Press.

Lemke JL. 2001. Articulating communities: Sociocultural perspectives on science education. Journal of Research in Science Teaching 38(3):296-316.

Shweder RA, Goodnow J, Hatano G, LeVine RA, Markus H, Miller P. 1998. The cultural psychology of development: One mind, many mentalities. In W. Damon \& R. M. Lerner (Eds.), Handbook of Child Psychology: Theoretical Models of Human Development (pp. 865-937). Hoboken, NJ, US: John Wiley \& Sons Inc. 


\author{
Materials \\ The Following Materials Are Needed to Perform the \\ EMG Experiment: \\ - $\quad$ iPhone/iPad or other smart device \\ - Download free AP from Backyard Brains ( \\ https://backyardbrains.com/products/) \\ - Backyard Brains Spiker Box for EMG \\ (https://backyardbrains.com/experiments/muscle \\ spikerbox) \\ - Wires for iPhone/iPad or other smart device to \\ connect to Spiker Box (included in Spiker Box) \\ - Rope to tie book (weights) \\ - Books or some weight \\ - Scale to measure the weights to be lifted
}

\section{Notes for the Instructor}

Ideally, this activity would be managed by two classroom instructors. Having the three divisions in the activities is helpful but can be hard to manage alone. A YouTube video describes the activities included in this module https://www.youtube.com/watch?x-yt$\underline{\mathrm{cl}=85114404 \& \mathrm{v}=9 \mathrm{gkkEuSttxo} \& \mathrm{x}-\mathrm{yt}-\mathrm{ts}=1422579428}$

An additional activity that can be implemented, depending upon availability of equipment, is observing the banding pattern of skeletal muscles if the class has a set of prepared microscope slides. A compound microscope with100x oil immersion lens is required for viewing muscle tissue banding.

If prepared slides with muscle are not available, skeletal muscle from fish, chicken, pig (pork), or cow (beef) meat can be purchased from a local grocery store or butcher shop. Do consider the culture of students in your class when selecting meat. For example, Muslim and Jewish students may avoid pork, whereas students practicing Hindu may avoid beef. A small, thin piece of meat (1 to $2 \mathrm{~mm}$ in length and $0.5 \mathrm{~mm}$ width) is placed on a glass microscope. Place the cover glass on top and glue it in place with super glue, or use fingernail polish when using the oil immersion lens.

When student groups are planning their presentation display or poster, students can build a sarcomere structure with pipe cleaners. The model can be used to explain the anatomy and illustrate how it moves with the sliding filament hypothesis in 2-D.

A model of the sarcomere model is shown in the YouTube link:https:/www.youtube.com/watch?x-yt$\mathrm{cl}=85114404 \& \mathrm{v}=9 \mathrm{gkkEuSttxo} \& \mathrm{x}-\mathrm{yt}-\mathrm{ts}=1422579428$

Alternatively, the instructor can encourage students to create a 3-D physical model to show more detail with myosin heads binding. A working model of skeletal muscle is a fun activity and more informative for students. A working model will also challenge students in thinking about the actual 3-D structure of sarcomeres and the various types of arrangements in the number of myosin heads and binding sites on actin. An example of a working sarcomere model is shown in Fig. 2 and highlighted in the YouTube link listed above.
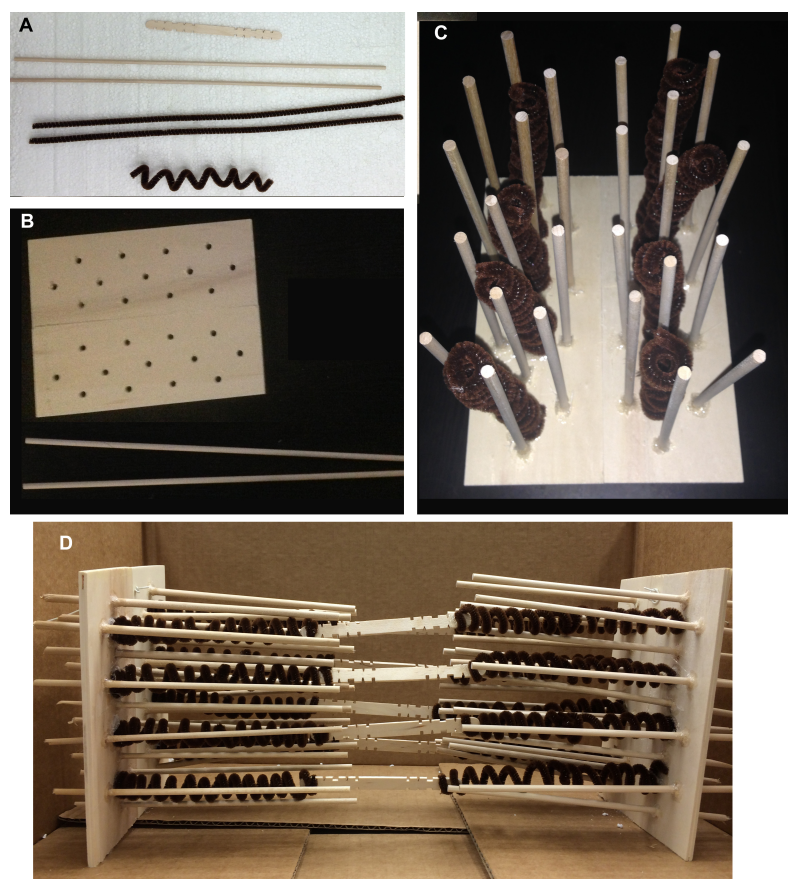

Figure 2. A model of the contractile elements of a sarcomere in skeletal muscle. a) Parts needed. b) Holes drilled are set locations for the dowels to be placed. c) Dowels represent the thin filaments and the coiled up pipe cleaner represent titin that later attach to the thick filaments. d) Completed model which can be shortened or lengthened for demonstration purposes. The wooden plates represent the Z-disks. Variations can be made such as adding myosin heads.

The EMG recordings using Backyard Brains (https://backyardbrains.com/) devices can be copied and graphed for various participants and weights the students used. Similarly, the data obtained using the models of the simulated myosin heads and amount of force (weight) with fish scale and Velcro strips on opposing tongue depressors can be graphed. One can graph the number of paired Velcro strips used and the weight measured on the fish scale to pull them apart. This of course depends on the surface area of the Velcro strips used, but generally the students will determine the more contact points the more force is needed to pull them apart.

If students have access to computers in the lab or at home, access the free version of SketchUp (http://www.sketchup.com/learn) to model the 3D aspects of skeletal muscle anatomy. We have done this activity with high school students and the students found it fascinating. 
The following images (Fig. 3) illustrate the model in stages as it was constructed in SketchUp. In the last the step, labels were added to identify the respective parts.

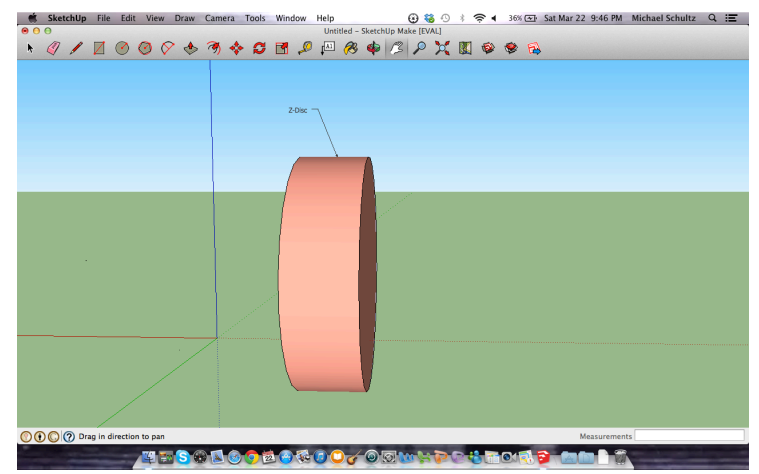

a.

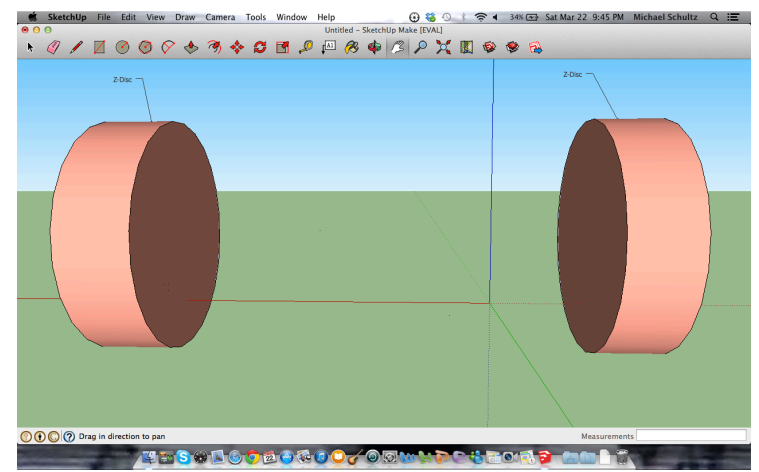

b.

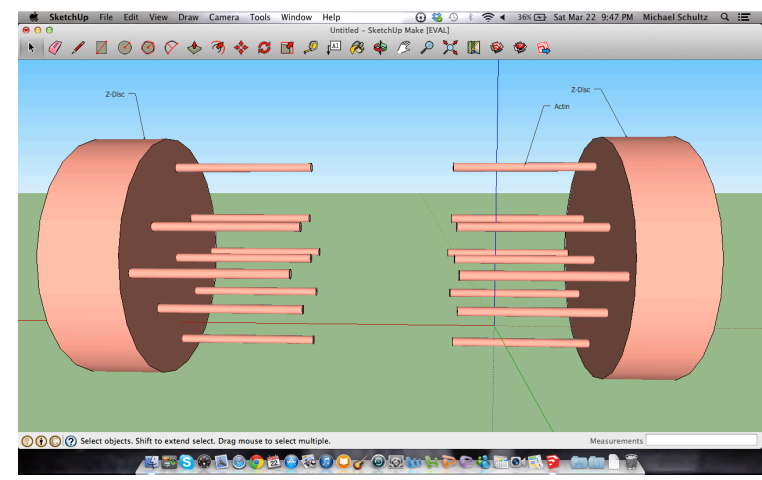

c.

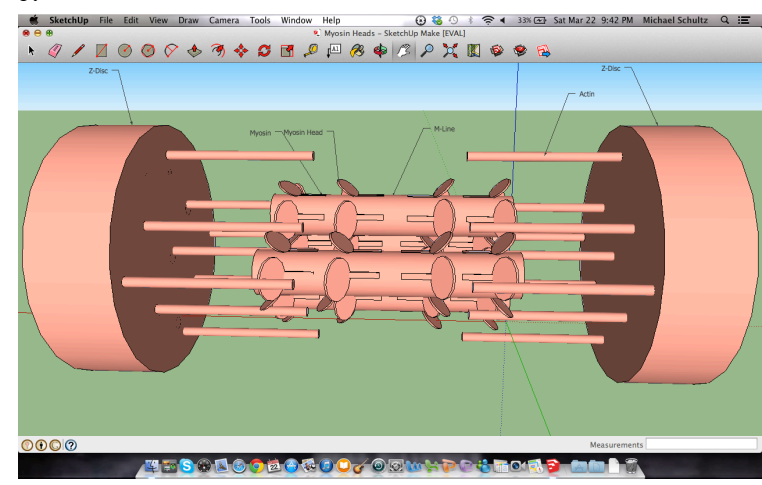

d.

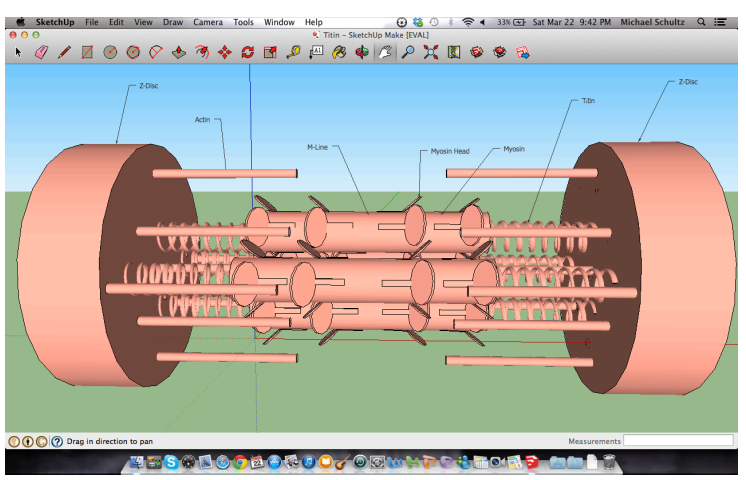

e.

Figure 3. Steps in building the sarcomere model (a- e) with SketchUp.

This module was presented to middle and secondary science classes in Kentucky. After implementing the modules, we reached out to researchers at the University of Kentucky at the Center of Muscle Biology to have SKYPE sessions with the classes. The middle and secondary students asked questions about muscular dystrophy; how one determines forces in living muscle; and how physical therapy impacts people with muscular dystrophy and many others. The development of this model occurred with college students working through the tasks. They relayed that they learned a substantial amount of muscle physiology and more about muscular dystrophy by developing and beta testing these tasks.

This Muscle Health Project is already spreading throughout Kentucky. Garrard High School in Lancaster, Kentucky, took on the project with a number of their science classes. The project was also presented at the Kentucky Science Teachers Association annual meeting and is now being targeted at the national level with NSTA (National Science Teachers Association) and at the international level with educational research on student learning outcomes from problem base and inquiry learning associated with NGSS.

The University of Kentucky undergraduate and graduate students as well as the faculty commented that they benefited from this interaction by enhancing their communication skills with the public about science. This type of interaction directly addresses concerns sbout the scientific discourse with the public (http:// www.pewresearch.org/science2015/).

The University highlighted this outreach activity as did the public school districts (http://uknow.uky.edu/ campus-news/uk-project-engages-next-generationkentuckians-tackle-health-problems ).

\section{Acknowledgments}

Funded through personal funds of Dr. Robin L Cooper. 


\begin{abstract}
About the Authors
Dr. Robin Cooper is an instructor of animal physiology and neurophysiology at the University of Kentucky. He received a double major with a BS from Texas Tech in 1983 and a PhD in Physiology from Texas Tech Medical School in 1989. He has been at the University of Kentucky since 1996.

Dr. Rebecca Krall earned an undergraduate degree in elementary education from Virginia Tech in 1988 , certified in science and literacy in grades K-8. After teaching science in grades six through eight, she earned a masters and doctorate in science education from the University of Virginia. She currently teaches science methods and effective uses of technology at the University of Kentucky. Her current research interests include developing K-8 teachers' scientific knowledge and pedagogy for creating authentic science experiences for students, the effect on student learning, and teachers' abilities to notice, interpret, and apply student thinking during their instruction.
\end{abstract}

Dr. Michael P. Schultz is a first-year internal medicine/pediatrics resident at Penn State Hershey Medical Center. He received his BS in Biology and Spanish and his MD from the University of Kentucky. He currently is interested in pursuing a career in an academic medical institution as an internal medicine/pediatric hospitalist.

Dr. Ann O'Neil is a physical therapist at Cincinnati Children's Hospital. She received a BS in Topical Studies Neuroscience and a DPT degree from the University of Kentucky. She is a certified clinical instructor and interested in becoming a Neurologic Clinical Specialist.

Dr. Esther E. Dupont-Versteegden graduated from State University Limburg at Maastricht, the Netherlands, with a BS in Movement Sciences. In 1995 she received a $\mathrm{PhD}$ in Physiology from the University of Texas Health Science Center at San Antonio, Texas. In 2006 she accepted her current position at the University of Kentucky, College of Health Sciences. 


\section{Appendix: Sample Tests}

\section{Used for both Pre Test and Post Test}

1. Rigor mortis can be explained by the in muscles postmortem.
A. bacterial growth
B. decreased amount of water
C. reduced concentration of ATP
D. increased concentration of $\mathrm{Mg} 2+$
E. release of lysosomal proteolytic enzymes

2. In which of the following general muscle group phenotypes would one most likely find the least amount of staining for enzymes associated with the Kreb's cycle or the electron transport chain?
A. slow red vertebrate muscle
B. Slow oxidative (Type I) vertebrate muscle
C. Fast oxidative (Type IIa) vertebrate muscle
D. Fast glycolytic (Type IIb) vertebrate muscle

3. In the figure the scale bar is $1 \mu \mathrm{m}$. What is the sarcomere length in the figure? (hint: estimate with marking your pencil. You can do the math with long hand.)

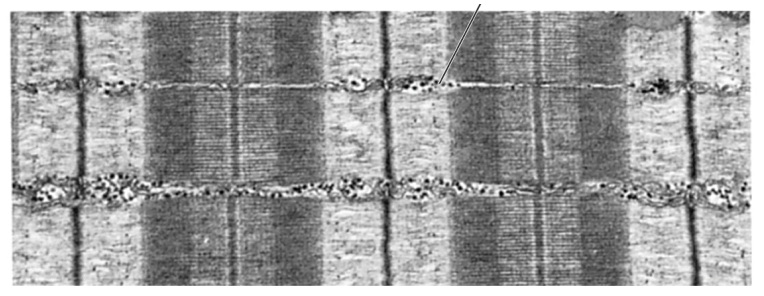
A. About 5 to $6 \mu \mathrm{m}$.
B. About 1 to $2 \mu \mathrm{m}$.
C. About 2 to $3 \mu \mathrm{m}$
D. About $13 \mu \mathrm{m}$
E. About 3 to $4 \mu \mathrm{m}$

4. Draw in the location of "Titin" for the middle sarcomere for a couple of the myosin units.

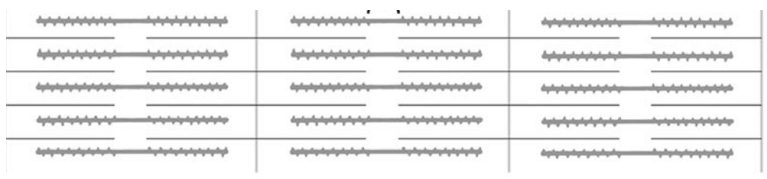

5. Where does the calcium come from that enters human skeletal muscle cells?
A. ECF (extracellular fluid)
B. SR (sarcoplasmic reticulum)
C. mitochondria
D. A, B, and C
E. A and B

6. Which of the following best describes an isometric contraction?

A. tension (or force) increases, but length stays the same.

B. tension (or force) stays the same, but length increases. 
C. tension (or force) stays the same, and length stays the same.

D. tension (or force) stays the same, but length decreases.

E. tension (or force) decreases, and length decreases.

\section{Which band does not change in length when skeletal muscle contracts or relaxes?}
A. A band
B. H band
C. I band
D. $\mathrm{S}$ band
E. sarcomere

\section{Open response question.}

In essay format, describe what you know about the disease of muscular dystrophy. In your response, explain the disease, its cause(s), treatment or cures, and at what age people are generally diagnosed with the disease.

9. In short essay format, describe what you know about the disease of muscular dystrophy. In your response, explain the disease, its cause(s), treatment or cures, and at what age people are generally diagnosed with the disease. 


\section{Mission, Review Process \& Disclaimer}

The Association for Biology Laboratory Education (ABLE) was founded in 1979 to promote information exchange among university and college educators actively concerned with teaching biology in a laboratory setting. The focus of ABLE is to improve the undergraduate biology laboratory experience by promoting the development and dissemination of interesting, innovative, and reliable laboratory exercises. For more information about ABLE, please visit http://www.ableweb.org/.

Advances in Biology Laboratory Education is the peer-reviewed publication of the conference of the Association for Biology Laboratory Education. Published articles and extended abstracts are evaluated and selected by a committee prior to presentation at the conference, peer-reviewed by participants at the conference, and edited by members of the ABLE Editorial Board. Published abstracts are evaluated and selected by a committee prior to presentation at the conference.

\section{Citing This Article}

Cooper RL, Krall RM, Schultz MP, O'Neil AS, Dupont-Versteegden EE. 2020. Educational modules of skeletal muscle anatomy and function with models and active data gathering related to muscular dystrophy. Article 64 In: McMahon K, editor. Advances in biology laboratory educaiton. Volume 41. Publication of the 41st Conference of the Association for Biology Laboratory Education (ABLE). https://doi.org/10.37590/able.v41.art64

Compilation (C) 2020 by the Association for Biology Laboratory Education, ISBN 1-890444-17-0. All rights reserved. No part of this publication may be reproduced, stored in a retrieval system, or transmitted, in any form or by any means, electronic, mechanical, photocopying, recording, or otherwise, without the prior written permission of the copyright owner.

ABLE strongly encourages individuals to use the exercises in this proceedings volume in their teaching program. If this exercise is used solely at one's own institution with no intent for profit, it is excluded from the preceding copyright restriction, unless otherwise noted on the copyright notice of the individual chapter in this volume. Proper credit to this publication must be included in your laboratory outline for each use; a sample citation is given above. 